\title{
Leading implementation of the management innovation value-based healthcare at a Swedish University Hospital
}

\author{
Kerstin Nilsson*1, Mette Sandoff ${ }^{2}$ \\ ${ }^{1}$ Institute of Health and Care Sciences, Sahlgrenska Academy, University of Gothenburg, Göteborg, Sweden \\ ${ }^{2}$ Department of Business Administration, School of Business, Economics and Law, University of Gothenburg, Göteborg, Sweden
}

Received: November 30, 2016

Accepted: January 2, 2017

Online Published: January 6, 2017

DOI: $10.5430 /$ jha.v6n1p51

URL: http://dx.doi.org/10.5430/jha.v6n1p51

\begin{abstract}
Objective: The aim of this study is to explore medical and care staff's experiences of leading the implementation of the management innovation, named value-based healthcare (VBHC) at a large Swedish University Hospital.

Methods: In this study an explorative design was used. Data was collected with individual open-ended repeated interviews with 20 members of four teams leading the implementation of VBHC. The interviews were transcribed verbatim and qualitatively analysed.

Results: Findings from this interview study showed that not all participants were comfortable with being appointed as leaders for the VBHC implementation process. Some found it rather too challenging instead. Participants described characteristics such as openness, visibility, approachability, and the ability to be a role model as necessary when leading implementation work. Leadership strategies emphasized were participation and involvement but also the ability to control implementation processes. Anchoring was effectuated by means of a pedagogical approach including dialogues and feedback before making step-by-step changes in everyday work itself.

Conclusions: This study shows that leadership is a challenging experience in the context of a team responsible for implementing VBHC, however commendable the management innovation in itself may be. The expectations connected to the leadership role in the context of VBHC implementation must be clarified. Awareness is needed of the extent of the mandates accorded to the care and medical staff appointed as leaders of VBHC teams, especially since care and medical staff are formally speaking not as managers.
\end{abstract}

Key Words: Leadership, Leadership characteristics, Leadership strategies, Management innovation, Value-based healthcare, Qualitative study

\section{INTRODUCTION}

Management innovation in healthcare may be seen as the implementation of new behaviours, routines and work processes aimed at facilitating healthcare provision. Innovation is often supported by administrative technologies and systems. ${ }^{[1]} \mathrm{A}$ specific management innovation includes both process and outcome as the intention is to influence processes and structures which can enable the organization to reach its goals. ${ }^{[2]}$ Management innovation also changes how managers carry out their managerial work. ${ }^{[3]}$ Healthcare organizations have

*Correspondence: Kerstin Nilsson, Prof.; Email: kerstin.nilsson@fhs.gu.se; Address: Institute of Health and Care Sciences, Sahlgrenska Academy, University of Gothenburg, Göteborg, Sweden. 
for a long time implemented evidence-based medical innovation led by health professionals even if this is not without problem. One problem that has been raised for example is the unwieldy explosion of clinical guidelines, ${ }^{[4]}$ while other researchers point at difficulties in implementing guidelines. ${ }^{[5]}$ It may be assumed that not all health professionals have the same experiences of implementing management innovations as they have of implementing evidence-based medicine. In this study the focus is on leading the implementation of a management innovation.

For the past decades the market-orientated model New Public Management (NPM) has been used to govern healthcare in Sweden. ${ }^{[6,7]}$ For some years, Swedish healthcare organizations have shown increased interest in the implementation of value-based healthcare (VBHC) as a management strategy. According to Porter and colleagues VBHC means increasing value for the patients through measuring both health outcomes and the costs of delivering outcomes. Healthcare should be developed based on measurement of health outcome. Furthermore they suggest organizing healthcare on the patients' medical conditions and full care cycles and bundle (episode-based) payment for healthcare. ${ }^{[8-10]}$ There is an ongoing debate amongst health professionals in Sweden as to whether the management innovation VBHC implies a break in the NPM trend or not. ${ }^{[11-14]}$ However, whether $\mathrm{VBHC}$ is a trend break from the NPM or not the process of implementing VBHC requires leadership. As early as 2007 Porter and Teisberg stated that working in line with VBHC called for leadership not just at top management level but also at the clinical level. ${ }^{[15]}$ Some studies about leadership in relation to implementing management innovations have been found, but according to Volberda and colleagues more knowledge is still needed about how management innovations are introduced and led in various organizations. ${ }^{[16]}$

Vaccaro and colleagues emphasized the need of differentiated leadership behaviour depending on the size of the organization, when management innovation is implemented in an organization. In smaller and less complex organizations more transactional leadership was advantageous and in larger and more complex organizations transformational leadership was an advantage. ${ }^{[17]}$ In a study in the banking sector it was found that transformational leadership was positive when the innovation related to unit-level. On organization-level transformational leadership correlated positively with an empowerment climate, which in turn contributed to improving unit-level management innovation. ${ }^{[18]}$ On the other hand an earlier study toned down the importance of the managers' individual transformational leadership and instead pointed at the importance of collective learning in the organization. However, leadership has a strong influence on organizational learning and thereby indirectly influences the organization's innovations. ${ }^{[19]}$ Transformational leadership has been found to influence organizational learning directly as well as organizational innovation and organizational performance in manufacturing organizations. ${ }^{[20]}$ All these studies highlighted the relation between leadership and implementing management innovations although in different ways.

In a study with an action research approach five critical points for adopting a management innovation in healthcare were found. Firstly, it is essential to develop a vocabulary describing the inner sense of the management innovation. Secondly, the new way of working and the change agents need to be accepted. Thirdly, an evolutionary adoption process including dialogues and reflection about the process is required. Fourthly, the change agents need to develop improvement expertise, and fifthly it is beneficial to use evidence-based actions and research-driven approaches. ${ }^{[21]}$ The need of an evolutionary adoption process as stated in this study by Hellström and colleagues, was also found in a study comparing the implementation of twelve different organization and management innovations in Swedish healthcare. ${ }^{[22]} \varnothing_{v r e t v e i t}$ and colleagues also pointed at the importance of the role of clinical leaders when implementing service innovations. ${ }^{[22]}$ Implementing innovations is always done in a context with its own traditions and culture; something the manager responsible for the implementation process needs to take into account. The managers therefore need to set goals for what the innovation is intended to contribute in the organization. They also need to understand how the innovation will influence the professionals' identity. ${ }^{[23]}$ Although several studies dealt with leadership in relation to implementing management innovations no studies were found about experiences of leading the implementation of VBHC; a gap this study aims to fill.

\section{Aim}

The aim of this study is to explore medical and care staff's experiences of leading the implementation of the management innovation, named VBHC at a large Swedish University Hospital.

\section{Method}

A qualitative design ${ }^{[24]}$ was used to explore how team members responsible for leading the implementation of the management innovation, VBHC. This study is part of a larger project in which the hospital's implementation process was followed for two years. Open-ended interviews were used as the data collection method in this study as the intention was to understand the team members' perspectives and experiences of leading this implementation. ${ }^{[25]}$ 


\subsection{Setting}

The hospital management director at a Swedish University Hospital decided to start the process of implementing VBHC in October 2013 with the establishment of four pilot teams, each one responsible for one group of patients with similar medical conditions. The members in these teams were responsible for leading the implementation work in their respective team. The hospital delivers care and treatment to both children and adults. The hospital has around 2,000 beds spread over 130 inpatient wards. The hospital's 180 outpatient wards are yearly visited by 1.2 million persons. About 16,700 persons are employed at the hospital.

\section{VBHC}

$\mathrm{VBHC}$ is a management strategy aiming at solving problems of quality and economy in healthcare. ${ }^{[8]}$ The idea is that this strategy will shift the focus from processes to health outcome and costs. The overall aim is to create as much value as possible for the patient in relation to cost. ${ }^{[8,9]}$ Quality in healthcare can increase thereby, patients' suffering can be reduced and better cost-effectiveness can be achieved. ${ }^{[8]}$ The members of the four pilot teams, which were supported by external management consultants the first three months, were expected to map the group of patients; define outcome measures; collect and analyse data; develop and implement improvement based on eventual identified weakness in the outcome measures; and finally continue to work in accordance with the strategy of VBHC. ${ }^{[8,9]}$

\subsection{Participants}

All members in the pilot teams, in all 20 persons, were invited to participate in this longitudinal interview study. The all gave their informed consent and agreed to participate in the study. The participants had different posts and professional qualifications. Nine of the participants were physicians whereof five were heads of department, three were clinicians and one was a clinician and healthcare developer. Three of the participants were registered nurses whereof two also worked part time as healthcare developers. Two were psychologists, whereof one worked part time as a healthcare developer and one was an occupational therapist with a managerial position. Finally, three logisticians and three controllers also participated. The participants' mean age was 46 (34-62). Eleven of the participants were male and nine were female.

\subsection{Data collection}

The first interview set was collected from March to April 2014, the second from November 2014 to January 2015 and the last from September 2015 to November 2015. Altogether the 59 individual interviews generated 36 hours of digitally

Published by Sciedu Press recorded interview material. One participant, who had not yet been introduced into the pilot-team declined participation at the third interview as being too newly employed. All interviews were carried out at the participants' office except one that was carried out in the participant's home. One theme in the thematic interview was about experiences of leadership related to the implementation work. A typical question to open up this theme was: "Can you tell me about your experiences of your role as leader when you work with implementing VBHC?" Depending on the interviewee's answer, follow-up questions were asked. All interviews were transcribed verbatim. A tentative analysis was made after each collected set of data to discover the main content. These analyses were sent to the participants and they were all given the opportunity to give feedback on the analysis. These tentative analyses were used in subsequent interviews.

\subsection{Study trustworthiness}

Lincoln and Guba used four concepts to describe the rigour of qualitative research, namely credibility, transferability, dependability and confirmability. ${ }^{[26,27]}$ In this study credibility was strengthened by the fact that all the members of the first four pilot teams accepted the invitation to participate in this study. They were of different age and gender and had varying experience and professional qualifications. This contributed to creating a comprehensive picture of leadership experiences. Credibility was further strengthened by means of individual interviews carried out three times during two years. These interviews were judged an appropriate data collection method to catch the complexity of experience involved in leading the implementation of VBHC. The analytical process contributed to forming suitable meaning units as a base for catching the variation of experiences. This study does not claim to generalize the findings, but it should be possible to transfer the findings to similar contexts where the implementation of a management innovation as VBHC is to be undertaken.

Transferability in this study was strengthened by illustrating the findings with excerpts from the interviews as well as by describing in detail the context where the study took place. However, it is always the reader's decision to what degree the findings are possible to transfer to another context. The fact that interviews were carried out three times might seem to increase dependability as that might contribute to consistency in the data. On the other hand, however, interviewing is an evolving process contributing to new insights over time. Questions raised during the tentative analysis were deliberately used during the forthcoming interviews to raise new questions thereby deepening the understanding of the phenomenon being studied. Furthermore, the open 
dialogue between the researchers contributed to judging the consistency in the content. The researchers' long experience of qualitative research and positions in different academic fields contributed to awareness of assumptions taken for granted. In qualitative studies confirmability is intended to ensure that the findings are a result of participants' experiences. This study does not give any answer as to how the leadership enacted was experienced by other staff in the organization. The findings only depict the participants' point of view and experiences. The interviews were recorded and transcribed verbatim and these transcripts were analysed with a high degree of accuracy that also reinforces the study's confirmability. The participants' confirmation of the tentative analyses contributes to showing the researchers' neutrality during the analytical process, since the participants had very few objections to these analyses, and they were on the level of wording.

\subsection{Data analysis}

The analysis was guided by a qualitative approach. ${ }^{[24,28]}$ Miles and Huberman ${ }^{[28]}$ stated that qualitative analysis consists of three steps: data reduction, data displaying and conclusion drawing/verification. The process of reducing data started, based on the study aim, with reading all the interview material. This reading aimed to give a sense of the whole and an overview of the material. As the interviews were read they were imported to NVIVO 10 (software for qualitative analysis QSR International Pty Ltd.). This programme was then used in the forthcoming analysis. The data reduction continued with identifying meaning units in the interviews. Condensed codes describing the content of the meaning units were then developed. These codes were later on used to display data by comparing similarities and differences between them and the units of meaning belonging to them. Through this comparison the data was grouped into categories. During this process an interpretation of the content in the categories was made. Based on this interpretation, conclusions could be drawn which led to establishing the themes in which the categories were interwoven and presented in the findings. Finally, verification of established themes was carried out by going back to the interviews and comparing descriptions in the themes with interview data. Furthermore, excerpts from the interviews contributed to illustrating the findings.

\subsection{Ethics}

According to the Swedish legislation approval from an Ethical Committee is not needed for this kind of interview study with health professionals. ${ }^{[29]}$ According to this law and the Declaration of Helsinki ${ }^{[30]}$ informed consent are required. Therefore, each participant was informed about the study aim and the data collection method as well as that partic- ipation was voluntary, that their interview data would be treated confidentially, and that they could withdraw at any time. Informed consent was obtained from all participants.

\section{RESUltS}

The analyses of the interviews resulted in three themes with their additional categories, which are interwoven in the themes.

\subsection{Challenges of being a leader}

Some participants did not experience themselves as leaders for the implementation of VBHC. They saw themselves just as workers with an assignment to carry out the job of implementation. Some participants without a management position in the hierarchical structure reduced their leadership responsibility by to some degree hiding themselves in the team: "Leading implementation - this is something we do together in the team, it is nothing that I do alone, but we all work together." (IP1). Another participant thought he/she was not the best leader even though the participant was nominated by the head of the department. Thus despite extensive competence in the field the participant was dubious about being a leader for the implementation process: "I have thought a lot about who is the perfect person to lead the implementation work; actually, I do not think it's me." (IP16). This doubtfulness was to some extent explained by her/his questioning the top-down decision to implement a strategy such as VBHC. The participant thought it would have been more advantageous to develop value for the patient based on a bottom-up approach.

As these participants did not fully see themselves as leaders they said they did not have any strategies related to needs of making changes related to VBHC work. Instead of seeing strategies for leading the implementation the participants focused on analysing the situation or the problem and tried to find out what kind of data was needed to direct the activities involved:

"I do not have any explicit strategies apart from trying to see the problem clearly. On a sound basis, we try to understand what data shows. How is it? Is it good or bad? That's step number one. If anyone complains about something you have to ask: is it really like this?" (IP10)

As stated, some of the participants did not see themselves as leaders which might be due to their estimation that their co-workers were so positive and autonomous that they could independently make the necessary decisions to implement VBHC. Therefore there was no need for a leader to motivate them. If the problem or situation was correctly described the co-workers were found to be capable of finding solutions 
themselves:

"I do not think I need to motivate many here. Everyone is very positive, but you have to describe the problem and get people interested in participating in solving the problem, and provide them with own space and their own responsibility. And it's very cool to see people grow." (IP 7)

\subsection{Personal characteristics in leadership}

Other participants talked about personal characteristics, which they had used in their leadership during the implementation phase. They said they were open persons, a characteristic they used when they informed those involved in the implementation work. They said that they were open with goals, status of the process, but also what they experienced as problems. Participants thought this openness was a necessary base to create the staff's engagement and involvement. One participant gave an example of this openness:

"I prefer to use other staff as a sounding board even if I myself may have good ideas how to understand something and also get it done. I do so as I think openness and involvement are important in change processes. I can say to a colleague 'you are fine at performance and outcome, what do you think about measuring this in VBHC' and then a lot of questions will be raised and discussed, which creates engagement." (IP15)

Participants stated that openness was a way to create curiosity and willingness to participate. However, participants said they did not force staff to participate in implementation activity if they did not feel comfortable with that. As leaders they thought it was important to respect that staff are at different stages in life and do not always have the capacity to engage in developmental work.

Participants also pointed out that they were visible and approachable. These characteristics made it possible to build relationships and to make the most of opportunities when the staff were ready and willing to make extra efforts in their developmental work. However, visibility and approachability demanded consideration and planning:

"You can't just be impulsive, things need to be scheduled, for example, I schedule where to eat lunch, this week I'll eat lunch here, the next there, it sounds boring, but there are no shortcuts. Another example is that I participate in workplace meetings both day and night at different wards. You have to be seen around if you are to be truly visible." (IP11)

Participants also pointed at the importance of being a role model for the staff involved in the implementation work. This also included personal characteristics such as being positive and enthusiastic and furthermore trying to create a

Published by Sciedu Press good atmosphere and working climate. Their own intense workload was expected to influence other staff so that they exerted themselves a little extra when work was piling up. They also thought they were more trustworthy if they themselves worked hard when necessary. By being a role model they could arouse enthusiasm in the implementation work but also make demands on employees:

"If you want others to perform well, you have to perform well yourself. It doesn't work otherwise. You have to manage your own part of the job, you have to ensure that you do that; otherwise you will not be seen as a credible leader." (IP 3)

\subsection{Strategies used to shoulder leadership}

Besides taking advantage of and using more personal characteristics, participants also described strategies used deliberately. One important strategy emphasized by participants was to make use of participation and always to have that in mind as the guiding star when leading. They considered that the more people became involved in the implementation work the more VBHC would become part of everyday work. Getting staff involved sometimes involved a more informal approach. One such example was to expand the circle of people when discussing VBHC by including the ones not directly involved for example at the coffee break. This was a conscious strategy to engage and motivate staff to work with VBHC:

"Yes, I actually think it is important to try to make them understand what they can contribute with so that they become involved; to show that this is the way we work; this is something I can do.” (IP20)

A first step when involving staff was to inform staff about the VBHC concept and what it means for the patients and how VBHC could contribute to creating value for the patients. Implementing VBHC also included working with results from measurements undertaken. In subsequent improvements, groups of staff need to be involved as it is important to gather experiences from different groups of staff at different wards to improve patients' healthcare:

"Well we have to bring some staff together in a small group; staff who can think and have antennae out, feel the attitudes in different wards, to work through changes. Nobody can do everything at once but working together in groups can create progress.” (IP1)

Participants related how they tried to take control of what was happening in different processes due to the implementation work. This kind of control could be effectuated by participants' direct questions to staff for example if they had performed activities in line with decisions made. Control of the processes could also be implemented by administra- 
tive staff who could produce statistics in relation to VBHC; statistics that were discussed in the teams. Based on knowledge about how the processes developed and functioned it was important to give feedback to those working with these processes. Participants considered that it was central to inform the co-workers how the implementation work was proceeding. Giving feedback about the process as well as about results obtained was also seen as a way to involve coworkers. Participants said it was important to give feedback about what the work was leading to and that they were aware of both positive and negative results emanating from VBHC work. Feedback could be given at formal meetings but also informally when meeting staff at lunchtime or at a coffee break:

"I use different contact surfaces. I always take the opportunity to inform about progress in VBHC and try to integrate different improvement initiatives based on monitoring measurements. When giving feedback we try to think about and discuss, 'what does this mean' and 'is this important to us'." (IP14)

Participants also talked about the importance of using a pedagogical approach when explaining what would be done and why. They tried to show that they had confidence in the staff and their ability to get VBHC implemented even if they were not experienced in VBHC. The pedagogical approach called for the participants' patience and use of concrete simple examples on what they wanted to be done and changed in the organization:

"Actually, I think I am very good at explaining in a simple way so that people understand. I never use difficult words for their own sake." (IP18)

Participants' change management strategy meant that improvements were made step by step. Participants were aware of the importance of instructing staff when a new routine or guidelines were to be implemented. A new routine not used in daily work called for repeated information. However almost all of them emphasized the necessity to create dialogues with staff as it was easier to understand the meaning of new guidelines through dialogues. Even if a new guideline was announced in the internal web-based communication channels available, it was necessary to communicate directly via dialogues since there was no guarantee that staff would read web-based communication. Participants thought it was easier to implement new routines when they were frequently used. Independent of frequency, participants assumed that the updating of guidelines contributed to motivating changes and to providing more value for the patients. After all that is said and done, creating engagement among the staff is of utmost importance:
"I think a very important part is to get involved and try to raise the level of consciousness among all the staff about their actually having great significance in the end to create value for patients. We will never be better than the weakest link in the chain. Every detail is important in the chain. Therefore everyone needs to be engaged." (IP3)

Accordingly, dialogue was used as a change management strategy for implementing new routines and guidelines for VBHC, but dialogues were also used to anchor the ideas that the changes were based on. The anchoring process was facilitated by implementing changes in small steps. The staff involved needed to understand why changes needed to be made, what the problem was, and alternative solutions and so on. Therefore participants stressed the importance of anchoring the changes:

"We've anchored changes very clearly, we've had meetings, regular meetings on the wards where all or at least many staff have participated, and I think there now is a pretty big engagement among staff for these changes." (IP4)

\section{Discussion}

The aim of this study has been to explore participating medical and care staff's experiences of leading the implementation of the management innovation, VBHC. The main findings were that not all participants were comfortable with being appointed as leaders for implementing VBHC. Some of them found it rather too challenging instead. By working in a team, personal leadership responsibility was reduced. Participants also described personal characteristics that were useful leadership qualities in the work of implementation. They found openness; visibility and approachability were favourable to good leadership as was being a role model when actually carrying out the work of implementation. Participation and involvement were leadership strategies that they emphasized and also the control of processes during implementation work. In their anchoring processes they gave priority to the necessity of creating dialogues and giving feedback. According to their experience, implementing VBHC included individual learning as a base for organizational learning and for this a pedagogical approach was used. This learning also included awareness that improvements needed to be undertaken step by step.

From the clinical leaders' point of view, implementing VBHC in clinical settings is seen as positive and valuable since this strategy to develop and manage healthcare has the potential to create value for the patients. ${ }^{[31]}$ Health professionals' wish to create value for the patients constitutes the main reason for working according to the strategies in VBHC. ${ }^{[8,10,32]}$ This is in line with health professionals' in- 
trinsic motivation to strive to do their best for the patients as well as to develop their medical and care competence. ${ }^{[33-35]}$ Health professionals' intention to do their best to create value for the patients probably explains their interest in participating in teams leading implementation work. Another explanation might be that implementing VBHC was seen as a break in the NPM trend. ${ }^{[12,14]}$ Even if concern for the patients is a key to increased engagement by health professionals, ${ }^{[36]}$ this study has solely focused on health professionals as leaders for implementing VBHC. Therefore no answers are given regarding patients' experiences of the implementation of VBHC. This fact does not reduce the importance of listening to the patients' voice. ${ }^{[37]}$

This study showed that being a member of a team appointed to lead the work of implementing VBHC was not without challenges. Some participants were uncomfortable at having a leading role. It is to be expected that the participants were used to implementing evidence-based medical innovation. However, implementing a management innovation presumably differs from implementing an evidence-based medical innovation. ${ }^{[4,5]}$ Perhaps the difference between implementing medical innovations and management innovations contributed to the experience of this being a challenging assignment. Another explanation might be that participants lacked leadership characteristics. However it is somewhat surprising that only some participants applied aspects of transformational leadership, since this type of leadership includes relational dimensions. ${ }^{[38,39]}$ Relationship is also of utmost importance when health professionals provide healthcare for patients. ${ }^{[40,41]}$ Transformational leadership has earlier been found to be favourable in large and complex organizations ${ }^{[17]}$ and one cannot deny that healthcare organizations are complex. ${ }^{[42]}$ The hospital in question here is without doubt a large organization. Further explanation might be that the participants themselves did not see their leading role within the professional role. Earlier studies have pointed out difficulties in recruiting, especially when it comes to physicians, since leadership positions appear to be unattractive to clinicians. ${ }^{[43]}$ The leadership role also appears to be more costly than beneficial, at least for women. ${ }^{[44]}$ Therefore, it is important for managers in an organization to be aware of the need of personal qualifications for leadership so that they try to identify people with the potential and interest to be future leaders.

This study has brought attention to some personal qualifications which participants themselves found useful when leading implementation work. These are worth being aware of when managers intend to identify and appoint leaders. However, it is not just a matter of appointing the "right" leaders, it is also important that the leaders have confidence in their

Published by Sciedu Press own capacity when they are appointed. The study results showed that some participants did not have any strategies for how to lead implementation work. This lack of strategies may indicate lack of confidence in themselves in a leadership role or may indicate that they quite simply did not see themselves as leaders. Earlier studies have shown that first and foremost physicians do not define themselves as leaders as they see themselves primarily as physicians irrespective of how much leadership duty they shoulder. Physicians have a strong physician identity. ${ }^{[45]}$ With this said about physicians in leadership positions, it must be pointed out that although not all the participants were physicians they were the largest professional group. Due to the power structure and hierarchy in healthcare ${ }^{[46]}$ one can assume that physicians played the dominant role in the teams.

Whichever professional group played the dominant role in the teams, it is important to know how clearly defined the leadership assignment was. Hellström and colleagues stated among other things that it is essential to develop the team's own vocabulary describing the inner sense of a management innovation. ${ }^{[21]}$ This study does not seek to answer whether this was done or not in this case, but other studies have shown that VBHC as a management strategy has been understood in different ways. ${ }^{[31,47]}$ Understanding the concept is fundamental. Therefore it is important for a hospital management team that decides to implement a management innovation as VBHC in its organization to set explicitly defined goals and to state clearly what work is expected of the team members. If an assignment is unclear, team members themselves will have to find out what and how things are to be done. A vague assignment might lead to participants to avoid shouldering their full responsibility.

Some participants discussed their use of personal characteristics and various strategies to lead their implementation work forward. Characteristics and strategies have been described in earlier studies. Only a few characteristics are described in this study and it is most likely that there are several more that are favourable in leadership. In an earlier study other personal leadership characteristics were identified among managers when they were interviewed about what they had learned in practice; these characteristics were "sensitivity", "clarity", "trustworthiness" and "ability to inspire". Sensitivity included listening. ${ }^{[48]}$ Furthermore in Nilsson and Furåker's study managers were shown to have developed the following leadership strategies: "creating buy-in", "timely action", "influencing one's superior", "delegation" and "careful recruitment". Anchoring as shown in this study was similar to creating buy-in in Nilsson and Furåker's study. The differences between characteristics and strategies in Nilsson and Furåker's study and this present study might be explained 
by differences between being a manager and being a leader. To lead without having a manager's authority requires other personal characteristics and strategies. When recruiting leaders, awareness of these differences is thus a requirement. However, health professionals appointed as leaders also need to step resolutely into the leadership role, even though this might involve stepping out of their comfort zone. Accordingly, when appointing leaders, attention must be paid to the context in which leadership is to be practised.

The participants' own opinions are reflected in the characteristics and strategies they described. They may have described them too positively. It is thus not certain that their descriptions correspond fully to the actual reality. According to the "Johari window"[49] there may be a difference between how an individual perceives her/his own personal characteristics and how others do. The results of this study do not show whether or not participants actually reflected on their leadership and the strategies they used and how these affected other staff during the work of implementation. A study among naval cadets showed that their work engagement increased if their leader showed a greater degree of transformational leadership. ${ }^{[50]}$ Perhaps the picture emerging here from the participants' viewpoint is overly positive. If we had interviewed other staff instead another picture may well have emerged. On the other hand, the picture given is a

\section{REFERENCES}

[1] Greenhalgh T, Robert G, Macfarlane F, et al. Storylines of research in diffusion of innovation: a meta-narrative approach to systematic review. Soc Sci Med. 2005; 61(2): 417-30. https: //doi.org/10.1016/j.socscimed.2004.12.001

[2] Birkinshaw J, Hamel G, Mol MJ. Management Innovation. Acad Manage Rev. 2008; 33(4): 825-45.

[3] Hamel G. The way, what, and how of management innovation Harvard business review. 2006; 84(2): 72-84.

[4] Greenhalgh T, Howick J, Maskrey N. Evidence based medicine: a movement in crisis? BMJ. 2014; 348: g3725. https : //doi.org/ $10.1136 / \mathrm{bmj} \cdot \mathrm{g} 3725$

[5] Grol R, Wensing M, Eccles M. Improving Patient Care : The Implementation of Change in Health Care. $2^{\text {nd }}$ ed. Wiley; 2013. https://doi.org/10.1002/9781118525975

[6] Christensen T, Lægreid P. Complexity and Hybrid Public Administration-Theoretical and Empirical Challenges. Public Organization Review. 2011; 11(4): 407-23. https://doi.org/10.1007/s111 15-010-0141-4

[7] Hasselbladh H, Bejerot E, Gustafsson RÅ. Beyond New Public Management - Institutional transformation in Swedish healthcare. [In Swedish]. Lund: Academia Adacta; 2008.

[8] Porter ME, Teisberg EO. Redefining Health Care - Creating ValueBased Competition. Boston: Harvard Business School Press; 2006. reflection of these participants' specific perception of their characteristics and strategies.

\section{Conclusions}

The team members' experiences of leading the work of implementing a management innovation as VBHC showed that they used personal leadership characteristics in combination with conscious strategies to fulfil their leadership responsibility. However not all team members were comfortable in their leadership role and found their leadership responsibility challenging. When describing the challenges, they emphasized the importance of clarifying what being a team member meant, including the responsibility of leading the implementation. The study findings show that it is not enough to have a well-defined and commendable management innovation even as in this case with support from the hospital management director. Appointing staff as team members with responsibility for implementing VBHC requires clear definitions of their roles and what team members are expected to do and achieve in their leadership role. Furthermore, those appointed to a leadership role must be appropriately prepared. Clarification of what leadership means and of the possible differences between leadership and management is also essential.

\section{CONFlicts OF INTEREST Disclosure}

The authors declare that they have no competing interests.
[9] Porter M, Lee TH. The Strategy that will fix health care. Harvard business review. 2013; 91(10): 50-70.

[10] Porter ME. What Is Value in Health Care? N Engl J Med. 2010; 23(363): 2477-81. https://doi .org/10.1056/NEJMp1011024

[11] Hansson SO. Medical Ethics and New Public Management in Sweden. Camb Q Healthc Ethics. 2014; 23(3): 261-7. https : //doi . or $\mathrm{g} / 10.1017 / \mathrm{S} 0963180113000868$

[12] Nordenstrom J. Value-based health care can improve health outcomes. Healthcare gets a new direction-the health personnel plays a key role. [In Swedish]. Lakartidningen. 2014; 111(39): 1631-2.

[13] Jarhult B, Secher E, Akner G. Value-based health care just as bad as New public management. [In Swedish]. Lakartidningen. 2014; 111(48): 2140-1.

[14] Hoglund PJ, Essen A, Choi S, et al. Value-based health care-strategy for efficient Swedish health care. Care should be organized based on what gives value to the patient. [In Swedish]. Lakartidningen. 2012; 109(47): 2159-61.

[15] Porter ME, Teisberg EO. How physicians can change the future of health care. Jama. 2007; 297(10): 1103-11. https ://doi.org/10 $.1001 /$ jama. 297.10.1103

[16] Volberda HW, Van Den Bosch FaJ, Mihalache OR. Advancing Management Innovation: Synthesizing Processes, Levels of Analysis, and Change Agents. Organization Studies. 2014; 35(9): 1245-64. https://doi.org/10.1177/0170840614546155 
[17] Vaccaro IG, Justin JP, Jansen JJP, et al. Management Innovation and Leadership: The Moderating Role of Organizational Size. Journal of Management Studies. 2012; 49(1): 28-51. https ://doi.org/10 $.1111 / \mathrm{j} .1467-6486.2010 .00976 . \mathrm{x}$

[18] Chang Y-Y. Multilevel transformational leadership and management innovation: Intermediate linkage evidence. Leadership \& Organization Development Journal. 2016; 37(2): 265-88. https: //doi.org/10.1108/LODJ-06-2014-0111

[19] Aragón-Correa JA, Cordón-Pozo E. Leadership and organizational learning's role on innovation and performance: Lessons from Spain. Industrial Marketing Management. 2007; 36(3): 349-59. https: //doi.org/10.1016/j.indmarman.2005.09.006

[20] Noruzy A, Dalfard VM, Azhdari B, et al. Relations between transformational leadership, organizational learning, knowledge management, organizational innovation, and organizational performance: an empirical investigation of manufacturing firms. International Journal of Advanced Manufacturing Technology. 2013; 64(5): 1073-85. https://doi.org/10.1007/s00170-012-4038-y

[21] Hellström A, Lifvergren S, Gustavsson S, et al. Adopting a management innovation in a professional organization. Business Process Management Journal. 2015; 21(5): 1186-203. https://doi.org/ 10.1108/BPMJ-05-2014-0041

[22] Øvretveit J, Andreen-Sachs M, Carlsson J, et al. Implementing organisation and management innovations in Swedish healthcare. J Health Org Manag. 2012; 26(2): 237-57. https://doi.org/10.1108/ 14777261211230790

[23] Bérard E, Bonnier C, Saulpic O, et al. Implementing managerial innovations: Lessons from two case studies. British Journal of Healthcare Management. 2015; 21(3): 125-9. https://doi.org/10.12968 /bjhc.2015.21.3.125

[24] Silverman D. Doing qualitative research. 4th, editor. London: Sage Publications; 2013.

[25] Patton MQ. Qualitative research \& evaluation methods. London: SAGE; 2002.

[26] Lincoln YS, Guba EG. Naturalistic inquiry. Newbury Park: SAGE Publications; 1985.

[27] Marshall C, Rossman GB. Designing qualitative research. 6th ed. Thousand Oaks: Sage Publications; 2016.

[28] Miles MB, Huberman AM. Qualitative Data Analysis An expanded Source-book. 2:ed ed. Thousand Oaks, Calif.: Sage Publications; 1994.

[29] The Act. The act of ethical trail of research concerning humans. Stockhom: Ministry of Education and Research. 2003; 460 (Amended SFS 2008: 192).

[30] World Medical Association. World Medical Association Declaration of Helsinki: ethical principles for medical research involving human subjects. Jama. 2013; 310(20): 2191. https ://doi .org/10.100 $1 /$ jama. 2013. 281053

[31] Andersson AE, Baathe F, Wickström E, et al. Understanding valuebased healthcare - an interview study with project team members at a Swedish university hospital. J Hosp Adm. 2015; 4(4): 64-72. https://doi.org/10.5430/jha.v4n4p64

[32] Porter ME. A strategy for health care reform-toward a value-based system. N Engl J Med. 2009; 361(2): 109-12. https://doi .org/ 10.1056/NEJMp0904131

[33] Kao AC. Driven to Care: Aligning External Motivators with Intrinsic Motivation. Health Serv Res. 2015; 50 (Suppl 2): 2216-22. https://doi.org/10.1111/1475-6773.12422

[34] Janssen PPM, De Jonge J, Bakker AB. Specific determinants of intrinsic work motivation, burnout and turnover intentions: a study among nurses. J Adv Nurs. 1999; 29(6): 1360-9. https://doi.or $\mathrm{g} / 10.1046 / \mathrm{j} \cdot 1365-2648.1999 .01022 . \mathrm{x}$

[35] Bååthe F. Physicians' engagement: qualitative studies exploring physicians' experiences of engaging in improving clinical services and processes. Göteborg: University of Gothenburg; 2015.

[36] Bååthe F, Ahlborg G, Edgren L, et al. Uncovering paradoxes from physicians' experiences of patient-centered ward-round. Leadersh Health Serv. 2016; 29(2): 168-84. https://doi.org/10.1108/ LHS-08-2015-0025

[37] Alharbi TS, Carlstrom E, Ekman I, et al. Experiences of personcentred care - patients' perceptions: qualitative study. BMC Nurs. 2014; 13(28): 1-9. https://doi.org/10.1186/1472-6955-1 3-28

[38] Bass BM. Two Decades of Research and Development in Transformational Leadership. European Journal of Work and Organizational Psychology. 1999; 8(1): 9-32. https://doi.org/10.1080/1359 43299398410

[39] Dionne SD, Yammarino FJ, Leanne E, et al. Transformational leadership and team performance. J Organ Change Manag. 2014; 17(2): 177-93. https://doi.org/10.1108/09534810410530601

[40] Pellegrini CA. Trust: The Keystone of the Patient-Physician Relationship. J Am Coll Surg. 2016; In press. https://doi.org/10.1 016/j.jamcollsurg. 2016.10.032

[41] Kane GM. Influences on the Patient-Physician Relationship: No Quick Fix. J Contin Educ Health Prof. 2016; 36(2): 138-9. https: //doi.org/10.1097/CEH.0000000000000071

[42] Edgren L, Barnard K. Complex adaptive systems for management of integrated care. Leadersh Health Serv. 2012; 25(1): 39-51. https://doi.org/10.1108/17511871211198061

[43] Styhre S, Roth A, Roth J. Who will lead the physicians unwilling to lead? Institutional logics and double-bind situations in health care leadership. Leadership \& Organization Development Journal 2016; 37(3): 325-40. https ://doi .org/10.1108/LODJ-10-201 2-0137

[44] Roth VR, Theriault A, Clement C, et al. Women physicians as healthcare leaders: a qualitative study. J Health Org Manag. 2016; 30(4): 648-65. https://doi.org/10.1108/JHOM-09-2014-0164

[45] Quinn JF, Perelli S. First and foremost, physicians: the clinical versus leadership identities of physician leaders. J Health Org Manag. 2016; 30(4): 711-28. https ://doi . org/10.1108/JHOM-05-201 5-0079

[46] Sebrant U. Emotion, power and identity. Emotional display of envy when taking on management roles in a professional hierarchy. $\mathbf{J}$ Health Org Manag. 2014; 28(4): 548-61. https ://doi.org/10.1 108/JHOM-11-2012-0220

[47] Fredriksson JJ, Ebbevi D, Savage C. Pseudo-understanding: an analysis of the dilution of value in healthcare. BMJ Quality and Safety. 2015; 2: 451-7. https://doi.org/10.1136/bmjqs-2014-003 803

[48] Nilsson K, Furåker C. Learning leadership through practice - healthcare managers'. Leadersh Health Serv. 2012; 25(2): 106-22. https : //doi.org/10.1108/17511871211221037

[49] Luft J, Ingham H. The Johari window, a graphic model of interpersonal awareness. Proceedings of the western training laboratory in group development. Los Angeles: University of California, Los Angeles; 1955.

[50] Breevaart K, Bakker A, Hetland J, et al. Daily transactional and transformational leadership and daily employee engagement. J Occup Organ Psychol. 2014; 87(1): 138-57. https://doi.org/10.111 1/joop. 12041 